it should be, and the recent introduction of radioactive sodium for skin-graft operations is an important advance in plastic surgery. The protective measures taken at Harwell give some indication as to how much protection the general public may be able to get in atomic warfare. The instruments devised for the detection of radiation are sensitive and accurate. The frog-suit and helmet that are worn by those who have to come into contact with highly contaminated areas are somewhat frightening, as shown in the illustration given; but nevertheless it is reassuring in that these workers can be thus protected.

In the sections dealing with fundamental aspects, the research and technical worker will find some interesting information. Among the topics discussed are the study of the unusual erystal structure of uranium, which is orthorhombic at room temperature (some more details have recently been published in an article by Dr. H. M. Finniston in Times Sci. Rev., No. 6 ; winter 1952); the effects of irradiation on the physical properties of crystals and glasses ; neutron diffraction; the splitting of carbon into three, and oxygen into four, helium nuclei by high energy $\mathrm{X}$-rays ; powder metallurgy, principally of beryllium, zirconium and niobium; and research on ceramics.

It would appear that the compilers of this excellent volume intend to encourage the average student of science to extend his knowledge of nuclear physics, and to assist him in this commendable purpose they provide, in an appendix, a list of books suitable for the non-scientist, another list for students up to honours degree standard, and in addition a list of papers on the generation of useful power from nuclear energy. Perhaps further accounts, similar to "Harwell", to bring the story up to date will aim at particular sets of readers, possibly one account for the general public and another more technical one for the student of nuclear energy in its various aspects.

\section{THE WORK OF G. F. FITZGERALD}

A SPECIAL meeting of the Royal Dublin Society A was held on October 30,1951 , to commemorate the centenary of the birth of George Francis FitzGerald (see Nature, 168, 930 ; 1951). A message of greeting was read from the president of the Institution of Electrical Engineers, of the Irish branch of which Prof. FitzGerald was the first chairman. The Physical Society, London, was represented by Prof. K. G. Emeléus, and personal messages of congratulation, received from Sir Edmund Whittaker and from Dr. G. F. C. Searle who remembered FitzGerald personally, were conveyed to the meeting by Prof. F. E. Hackett. Slides and exhibits of some of FitzGerald's models, letters and experiments were shown.

The major part of the meeting was devoted to the reading of five papers dealing with FitzGerald as a man and a scientific worker and with the FitzGeraldLorentz contraction and its relation to the theory of relativity. The text of these papers, together with two illustrations of FitzGerald as he was in 1878 and 1897, is included in the FitzGerald Memorial Number of the Scientific Proceedings of the Royal Dublin Society*. In the first paper, Prof. Hackett discusses the character of FitzGerald as revealed by his letters to Heaviside and gives examples of the several

* Scientific Proceedings of the Royal Dublin Society, 26 (N.S.), No. 1 : Fitzgerald Memorial Number. Pp. $54+3$ plates. (Dublin: brilliant suggestions proposed but not actively pursued by FitzGerald. This is followed by a paper by Prof. H. E. Ives, who, after a brief historical survey of the FitzGerald contraction, derives, using the method of approach of Poincaré's principle of relativity instead of the more usual invariance of the Michelson-Morley experiment, the exact value of the FitzGerald contraction together with the accompanying change of clock frequency perceived by Larmor. Prof. Tves concludes with a brief discussion of the experimental evidence for the contraction and adds some interesting remarks concerning the ether.

Prof. W. H. McCrea discusses some paradoxes of the FitzGerald contraction and their resolution, and Dr. G. J. Whitrow the theories of relativity of Galilean frames with particular reference to E. A. Milne's work. Finally, Prof. J. L. Synge, in a paper entitled "Effects of Acceleration in the Michelson and Morley Experiment", offers an explanation, which be admits may appear fantastic but which is capable of direct experimental test, of D. C. Miller's observations in his 1933 repetition of the MichelsonMorley experiment. The explanation is based on G. H. F. Gardner's theory of the behaviour of a rigid body in accelerated motion. Because of the horizontal position of the interferometer, the original MichelsonMorley experiment is extremely poor as a check on Gardner's theory. An interferometer firmly integrated with the earth and with at least one of the two arms of the interferometer inclined at $45^{\circ}$ to the horizontal is required, and such an instrument, Prof. Synge estimates, even with an arm-length of only $20 \mathrm{~cm}$., compared with Miller's $3,000 \mathrm{~cm}$., would give a fringe shift of a full fringe on rotation about a vertical axis. Reference may be added here to an experiment on these lines made by Prof. R. W. Ditchburn and O. S. Heavens (see Nature, 170, 705 ; 1952).

\section{AMERICAN-ASIAN FLORISTIC RELATIONSHIPS}

$\mathrm{T}$ HE floristic relationship between eastern Asia and eastern North America is the subject of a considerable memoir by Hui-Lin Li (Trans. Amer. Phil. Soc., New Ser., 42, 2, 371; 1952), the subject being one which has interested plant geographers ever since Asa Gray's important paper on the subject in 1840 .

While the present work broadly confirms the basic ideas established one hundred years ago, it reviews and revises the data in the light of modern concepts of taxonomy, nomenclature, plant geography and genetics. There is, in fact, a close floristic relationship between eastern Asia and North America, this being particularly marked in the east. Many genera which are common to, and dominant elements in, the two floristic regions have also a wide, general distribution and are therefore less useful in establishing relationships between the two continental regions. But there are many other less widespread genera which are of particular value in this study. Those genera, common to both continents, which are better developed in western than in eastern North America are considered as primary genera of western North America, whence they have spread eastwards into eastern North America and westwards into adjacent parts of north-eastern Asia. Their range is thus more or less continuous.

Leaving aside the many pan-tropical genera, a number of tropical and subtropical genera are known 